\title{
Dissecting Cancer Pathways and Vulnerabilities with RNAi
}

\author{
T.F. Westbrook, F. Stegmeier, And S.J. Elledge \\ Howard Hughes Medical Institute, Department of Genetics, Harvard Partners Center for Genetics and Genomics,
} Harvard Medical School, Boston, Massachusetts 02115

\begin{abstract}
The latest generation of molecular-targeted cancer therapeutics has bolstered the notion that a better understanding of the networks governing cancer pathogenesis can be translated into substantial clinical benefits. However, functional annotation exists for only a small proportion of genes in the human genome, raising the likelihood that many cancer-relevant genes and potential drug targets await identification. Unbiased genetic screens in invertebrate organisms have provided substantial insights into signaling networks underlying many cellular and organismal processes. However, such approaches in mammalian cells have been limited by the lack of genetic tools. The emergence of RNA interference (RNAi) as a mechanism to suppress gene expression has revolutionized genetics in mammalian cells and has begun to facilitate decoding of gene functions on a genome scale. Here, we discuss the application of such RNAi-based genetic approaches to elucidating cancer-signaling networks and uncovering cancer vulnerabilities.
\end{abstract}

Tumorigenesis is a multistep process during which incipient cancer cells acquire a myriad of genetic and epigenetic alterations. Such alterations confer numerous changes in cell behavior, including inappropriate survival and proliferation (Hanahan and Weinberg 2000). However, the genetic perturbations underlying these aberrant cell behaviors are concealed by the complex instability of most cancer cell genomes. As a consequence, the goal of identifying genes promoting (oncogenes) and restraining (tumor suppressors) tumorigenesis has proved challenging. Much of our understanding of cancer cell biology has been derived from biochemical and reverse genetic approaches in which a gene of interest is interrogated for its relationships to other gene products and its roles in various cellular processes. This approach has yielded significant insight into select signaling networks and provided a molecular basis for much of cancer biology. However, the majority of this insight has been directed to a relatively small proportion of genes in the human genome, raising the likelihood that many genes underlying cancer cell phenotypes and, thus, potential drug targets have yet to be identified. Forward genetic approaches offer a plausible solution to this challenge, allowing one to elucidate genes underlying a given phenotype without a priori knowledge of its biochemical functions. Indeed, the unbiased genetic screens applied in yeast, worms, and flies have often provided entry points into studies of cancer-related phenomena that have been recalcitrant to other approaches. Until recently, mammalian cells have been refractory to loss-of-function genetic approaches due to the lack of time- and cost-efficient tools to create recessive, defined perturbations in somatic cells. The discovery of RNA interference (RNAi) and the subsequent exploitation of this biological phenomenon as a means to manipulate gene expression have begun to revolutionize mammalian genetics (Paddison and Hannon 2002; Brummelkamp and Bernards 2003; Hannon and Rossi 2004). This perspective focuses on how emerging RNAi-based genetic strategies could be used to delineate the genetic networks that govern tumorigenesis and rapidly identify promising molecular targets for cancer therapy.

RNAi is a gene regulatory pathway that is triggered in response to dsRNA molecules (Hannon 2002; Dykxhoorn et al. 2003). Since its formal description in Caenorhabditis elegans by Fire and colleagues (Fire et al. 1998), RNAi has been linked to gene-silencing phenomena in evolutionarily diverse organisms. RNA triggers have been shown to suppress gene expression by a variety of mechanisms, including mRNA degradation, loss of protein translation, and transcriptional silencing (Meister and Tuschl 2004). Although the complexities of these phenomena are far from understood, the hallmark of RNAi is the cleavage of dsRNA into 21- to 22-nucleotide molecules, or small interfering RNAs (siRNAs), by an RNase III enzyme, Dicer (Bernstein et al. 2001). These cleavage products are unwound and incorporated into an RNA-induced silencing complex (RISC), which utilizes the siRNA to identify homologous sequences within cognate mRNAs and degrade the mRNA (via the ribonuclease Ago2) or suppress translation from the mRNA template (Hannon 2002; Dykxhoorn et al. 2003).

Since its discovery, RNAi has become a common tool for loss-of-function studies in invertebrates (Drosophila melanogaster and C. elegans) in which gene-specific silencing is induced by the introduction of long dsRNAs. However, the use of such long dsRNA as an RNAi trigger is not plausible in mammalian somatic cells due to the PKR- and interferon-mediated responses to long-dsRNA molecules, which induce sequence-independent degradation of mRNAs and global repression of protein synthesis (Minks et al. 1979; Manche et al. 1992; Stark et al. 1998). Tuschl and colleagues circumvented this nonspecific toxicity by demonstrating that chemically synthesized siRNAs were sufficient to target complementary mRNAs for destruction but did not elicit the interferon response (Elbashir et al. 2001). Since this watershed event, the use of RNAi as a tool to decipher gene function has become commonplace in mammalian cell biology. As our under- 
standing of RNAi biochemistry has evolved, so have the methods by which this endogenous pathway of gene regulation is harnessed for studying mutant phenotypes (Paddison and Hannon 2002; Brummelkamp and Bernards 2003; Hannon and Rossi 2004). siRNAs can be transfected directly into target cells, enabling studies of transient phenotypes that can be assayed in cells amenable to transfection. Alternatively, silencing triggers can be encoded genetically by small inverted repeats that express short hairpin RNAs (shRNAs) (Brummelkamp et al. 2002; Paddison et al. 2002; Sui et al. 2002; Yu et al. 2002). These shRNA transcripts form a stem loop structure that is processed by endogenous nuclease(s) into RNAs that can be incorporated into RISC. The design of these shRNAs was based on the discovery of endogenous triggers of the RNAi machinery, called small temporal RNAs or microRNAs (miRNAs) (Grishok et al. 2001; Hutvagner et al. 2001; Ketting et al. 2001). Initially, shRNAs were expressed from polymerase III (pol III) promoters such as U6 or H1 (Brummelkamp et al. 2002; Paddison et al. 2002; Sui et al. 2002; Yu et al. 2002), because of the precisely defined initiation and termination sequences for pol III. However, increasing knowledge of miRNA biogenesis has allowed flexibility in promoter usage as well as design of silencing triggers that more closely mimic endogenous miRNA transcripts (discussed below), presumably allowing more efficient processing of the targeting sequence. Importantly, shRNAs and miRNAs can be stably expressed from plasmid, retroviral, or lentiviral contexts, thus allowing long-term analyses of mutant phenotypes.

The ease of delivery and efficiency of sequence-specific gene silencing elicited by dsRNAs has facilitated genome-scale screens for modifiers of several cellular and organismal phenotypes in invertebrates (see, e.g., Ashrafi et al. 2003; Lee et al. 2003; Boutros et al. 2004; Baeg et al. 2005; DasGupta et al. 2005; Sieburth et al. 2005). In contrast, RNAi has predominantly been used in mammalian cells as a reverse genetic tool to eliminate specific gene function. However, large collections of array-format siRNA libraries have been generated, and, more recently, retrovirus-encoded shRNA libraries targeting the human and mouse genomes have been developed (Berns et al. 2004; Paddison et al. 2004; Silva et al. 2005), ushering in a new era of forward-genetic screening in mammalian systems. The advantages of these different formats for RNAi-mediated gene discovery have been reviewed in depth (Silva et al. 2004; Willingham et al. 2004). We discuss the impact these new functional genetic tools will have on cancer biology and drug target discovery.

\section{DELINEATING CANCER-RELEVANT PATHWAYS AND DRUG TARGETS}

The majority of traditional chemotherapies were discovered based on their ability to kill rapidly proliferating cancer cells. Unfortunately, these therapies inhibit gene products and cellular processes that are required in rapidly dividing normal tissues (e.g., hematopoietic), resulting in a delicate balance between killing cancer cells and toxicity to the patient. The most recent generation of so-called targeted cancer drugs is designed to inactivate the very oncogenic lesions that contribute to the aberrant survival and proliferation of tumor cells, and has yielded remarkable success in some malignancies (Slamon et al. 1989; Druker et al. 1996; Druker 2002; Lynch et al. 2004; Paez et al. 2004; Sordella et al. 2004). The potential of these molecular-targeted therapies is embedded in the emerging concept of "oncogene addiction," or oncogene dependence (Weinstein 2002), which suggests that cancer cells are genetically or epigenetically reprogrammed upon suffering an oncogenic lesion such that the initiating lesion is required for maintenance of tumor cell phenotype(s). Support for such a concept comes from both in vitro and in vivo experiments. For instance, numerous studies have utilized conditional mouse models of cancer to explore oncogene dependence. In many of these models, expression of the initiating oncogene was required for tumor maintenance, with tumor cells undergoing differentiation, arrest, and/or apoptosis upon removal of the initial oncogenic stimulus (Jonkers and Berns 2002, 2004). Observations from the clinic also support the concept of oncogene dependence. Imatinib has been used to inhibit the aberrant signaling from BCRABL, c-KIT, and PDGFRA in the treatment of chronic myelogenous leukemia (CML), gastrointestinal stromal tumor (GIST), and hypereosinophilic syndrome (HES), respectively (Druker et al. 1996, 2001; Tuveson et al. 2001; Demetri et al. 2002; Cools et al. 2003). Notably, many patients suffering relapsed CML have incurred resistance mutations in the BCR-ABL fusion, corroborating the role of this lesion in disease maintenance (Gorre et al. 2001). Since the landmark success of imatinib, other molecular-targeted therapies have demonstrated efficacy, with trastuzumab (Her2/neu-blocking antibody) used to treat breast cancers with HER2/neu amplification/overexpression and gefitinib used to target non-small-cell lung cancers (NSCLC) with mutant EGFR (Slamon et al. 1989; Lynch et al. 2004; Paez et al. 2004; Sordella et al. 2004). Whereas these experimental and clinical observations support the concept of oncogene addiction, the underlying mechanisms by which cancer cells become dependent on such perturbations remain unclear. Nonetheless, the concept of oncogene dependence invokes an important vulnerability of cancer cells: novel gene-gene interactions that do not exist in counterpart normal cells. Consequently, identifying the genetic and epigenetic perturbations that contribute to tumor genesis and exploring the unique genetic relationships that result from these lesions are central goals in cancer biology.

\section{IDENTIFYING MODULATORS OF KNOWN CANCER PATHWAYS}

A plethora of genetic and epigenetic lesions have been implicated in cancer initiation and progression. Some of these lesions are highly represented in human cancers (e.g., p53, Rb). Indeed, it has been hypothesized that the function of a few key oncogenes and tumor suppressors must be dysregulated, either by direct insult or by alterations in upstream and downstream regulators, in all can- 
cer types. Therefore, delineating the networks that regulate these key cancer pathways represents a promising approach to identifying new regulators of tumorigenesis. Recently, several forward genetic screens have incorporated this strategy in the context of Drosophila and mammalian tissue culture cells. Such screens have often relied on reporter constructs in which a promoter of interest is linked to a gene encoding a fluorescent or luminescent protein (e.g., GFP, firefly luciferase), with regulators of the reporter isolated by fluctuations in fluorescence or luminescence intensity. For instance, one can identify pathways that regulate transcription of a gene of interest by linking regulatory sequences from its promoter to a reporter gene. We have applied this strategy to identify repressors of hTERT gene transcription (Lin and Elledge 2003). hTERT is the catalytic subunit of the telomerase enzyme, and its activity is absent from most somatic tissues but is up-regulated in $>90 \%$ of human cancers. Because amplification and translocations of hTERT are not observed in cancer, we surmised that pathways responsible for repressing hTERT transcription might be dysregulated during tumor genesis and thus represent tumor suppressor activities. Supporting this hypothesis, an antagonist of oncogenic Myc signaling (MAD1), an effector of the TGF- $\beta$ tumor suppressor pathway (SIP1), and a bona fide tumor suppressor (MENIN) were all identified as repressors of hTERT transcription in this screen. Whereas this screen employed a retroviral mutagenesis strategy, application of RNAi-based libraries in a similar context will undoubtedly elucidate new pathways controlling hTERT expression.

Some oncogenes and tumor suppressors have already been organized into well-characterized pathways, and several groups have recently performed RNAi-based screens to identify new modulators of these critical pathways using synthetic promoter elements that drive transcription in response to pathway activation. The Hedgehog (Hh) and Wnt-Wingless signaling pathways play crucial roles in development, stem-cell homeostasis, and tumorigenesis (Nybakken and Perrimon 2002; Logan and Nusse 2004). Using an array-format library of dsRNA directed against the Drosophila genome, Perrimon and colleagues performed a screen for modulators of a Wnt-responsive luciferase reporter (DasGupta et al. 2005). This screen isolated most of the known elements of the Wnt pathway. In addition, a plethora of novel positive and negative regulators of Wnt signaling were identified, underscoring the complexity of the genetic networks that may impinge on Wnt-dependent processes. In a similar strategy, the Beachy laboratory screened for components of the Hh pathway using a Hh-responsive reporter (Lum et al. 2003). Again, both known and previously unrecognized regulators of $\mathrm{Hh}$ signaling were isolated. Furthermore, two components of the Wnt pathway were identified as modulators of $\mathrm{Hh}$ signaling, providing potential nodes of cross talk and/or co-regulation between these two pathways.

Similar approaches to identifying new modulators of cancer-relevant pathways have been applied in mammalian cells, although predominantly with smaller RNAi libraries directed against gene families. Using an shRNA library targeting deubiquitinating enzymes (DUBs), the Bernards and D'Andrea laboratories identified a negative regulator (USP1) of the monoubiquitination of the Fanconi anemia complementation group D2 protein, or FANCD2 (Nijman et al. 2005). Fanconi anemia is a recessive genetic disorder characterized by genomic instability, hypersensitivity to DNA-crosslinking agents, and a predisposition to a variety of malignancies (D'Andrea 2003). FANCD2 monoubiquitination is hypothesized to be a critical regulatory event in the Fanconi anemia pathway (Meetei et al. 2003), and USP1 was found to antagonize this event (Nijman et al. 2005). Using the same DUB-shRNA library and an NF- $\kappa B-$ responsive reporter, Bernards and colleagues also identified an antagonist of NF- $\kappa \mathrm{B}$ signaling, the familial cylindromatosis tumor suppressor (CYLD) (Brummelkamp et al. 2003). Loss of CYLD confers benign tumors arising from sweat glands (cylindromas) of the head and neck. Intriguingly, pharmacological inhibition of $\mathrm{NF}-\kappa \mathrm{B}$ led to regression of cylindromas, suggesting that aberrant activation of the $\mathrm{NF}-\kappa \mathrm{B}$ pathway may contribute to the pathogenesis of this disease. Schultz and colleagues performed a similar screen for modulators of NF- $\mathrm{KB}$ signaling, employing a much larger siRNA library targeting approximately 8000 human genes (Zheng et al. 2004). In addition to several established components of the NF- $\kappa$ B pathway, $>90$ genes were implicated in NF- $\kappa \mathrm{B}$ signaling, although future study is needed to determine the specificity of these effects.

\section{IDENTIFYING NOVEL CANCER PATHWAYS}

The above approaches will undoubtedly serve to illuminate networks that impinge upon and transduce the effects of those genes already heavily implicated in human tumorigenesis. However, cancer cells exhibit complex phenotypes, including altered responses to mitogenic and cytostatic signals, resistance to programmed cell death, immortalization, neoangiogenesis, and invasion and metastasis (Hanahan and Weinberg 2000), for which our knowledge of the underlying molecular mechanisms is far from complete. Genetic screens in model organisms have been instrumental in advancing our understanding of cell proliferation, apoptosis, migration, and the developmental programs that regulate these cell behaviors in vivo. Furthermore, traditional genetic screens in $C$. elegans and Drosophila have recently been complemented with systematic genome-scale RNAi-based screens for genes that regulate cellular or organismal phenotypes such as viability, proliferation, longevity, and fat storage (Ashrafi et al. 2003; Lee et al. 2003; Boutros et al. 2004; Hamilton et al. 2005). Yet, some cancer phenotypes (e.g., neoangiogenesis) cannot be studied in these model organisms, and the components and/or wiring of several mammalian oncogene/tumor suppressor pathways are not conserved in these organisms. Therefore, dissecting cancer cell phenotypes by means of forward genetic screens in mammalian cells is an important approach toward our understanding of cancer biology and therapeutic design.

Forward genetics has already been used with some success in mammalian cancer biology in the form of gain-of- 
function screens. For instance, the human Ras oncogene was cloned as a transforming activity by transfecting mouse fibroblasts with genomic DNA fragments from a human bladder cancer (Goldfarb et al. 1982; Shih and Weinberg 1982). More recently, retroviral cDNA libraries have been used to probe such phenotypes as cellular senescence and anoikis (Peeper et al. 2002; Shvarts et al. 2002; Douma et al. 2004). Although large collections of mammalian siRNA and shRNA libraries have only recently been described (Berns et al. 2004; Paddison et al. 2004; Silva et al. 2005), successful application of these reagents in loss-of-function screens has already begun to emerge. Cooke and colleagues provided the first example of such a success in their siRNA-based screen for modulators of TRAIL-induced apoptosis (Aza-Blanc et al. 2003). TRAIL is a member of the tumor necrosis factor (TNF) superfamily, and this ligand has gained attention because of its ability to induce apoptosis in a tumor-cell-specific fashion (Ashkenazi and Dixit 1999). Using an array-based platform of chemically synthesized siRNAs targeting 510 human genes (enriched for human kinases), Aza-Blanc et al. identified several known mediators of TRAIL-induced death, previously uncharacterized genes that affect TRAIL activity, as well as genes that synthetically interact with the TRAIL pathway (see below). More recently, siRNA collections have also been used to isolate genes required for cell proliferation and viability in vitro (Kittler et al. 2004; MacKeigan et al. 2005).

In addition to these array-format siRNA-based screens, retrovirus-encoded human shRNA libraries have been employed as pooled collections. Such libraries enable stable loss-of-function genetic selections, and use in a pooled format circumvents the prohibitive cost and labor involved in array-format genome-scale screens (for review, see Silva et al. 2004; Willingham et al. 2004). Bernards and colleagues used this strategy to identify new antagonists of the p53 pathway (Berns et al. 2004). Human fibroblasts were engineered with a temperaturesensitive allele of SV40 LT, enabling limitless replicative potential at the permissive temperature. Culturing these cells at the nonpermissive temperature elicits a p53-dependent arrest, allowing shRNAs that enabled proliferation under this selective pressure to be isolated. In addition to p53 itself, five candidate genes were identified. Reduced expression of each candidate prevented p53-dependent induction of the CDK-inhibitor $\mathrm{p} 21^{\mathrm{CIP} 1}$ and proliferative arrest, suggesting that these genes antagonize p53 function on some level. Determining the role(s) of these modifiers of in vitro culture-based cellular mortality in other p53-dependent processes (including tumor suppression) will be an important avenue for future study.

Pooled shRNA libraries have also been employed in an in vitro screen for candidate tumor suppressors (Westbrook et al. 2005). Using a pre-transformed cell line engineered from primary human mammary epithelial cells (HMECs), we isolated shRNAs that elicited anchorageindependent proliferation, a common phenotype of cancer cells. In the context of this system, previously characterized regulators of cell proliferation and survival were identified, including two bona fide human tumor sup- pressors: PTEN and TGFBR2 (Vivanco and Sawyers 2002; Siegel and Massague 2003). REST/NRSF, a transcriptional repressor of neural genes (Chong et al. 1995; Schoenherr and Anderson 1995), was also isolated as a suppressor of epithelial cell transformation. The unanticipated role for REST as a human tumor suppressor was supported by both human genetic evidence and observations implicating REST as an antagonist of PI3K signaling, a pathway with well-established roles in cancer. Although it was not unexpected that modifiers of PI3K signaling may be isolated (hyperactivation of PI3K can transform HMECs in this genetic context), the implication that REST function may be perturbed in human cancer provides a potential mechanism for the aberrant expression of neural genes observed in many epithelial cancers.

Unanticipated insights into cancer biology like the one above underscore the potential of unbiased genetic screens in dissecting cancer-related processes. In vitro models of many of these processes, including survival, growth-factor dependency, anoikis, invasion, migration, and 3-dimensional organization, already exist in some forms and will surely be exploited as platforms for genetic screens and selections. Indeed, our ability to explore these phenomena should be limited only by our ability to faithfully recapitulate these phenotypes in vitro or to devise forward genetic approaches to investigate them in vivo. Performing in vivo screens offers substantial promise to investigating complex biological processes for which we have a poor understanding of the cellular attributes that culminate in the phenotype. For instance, metastasis is a multistep process requiring invasion, intravasation, survival in circulation, extravasation, and survival and proliferation at a distant site (Chambers et al. 2002). Genetic screens in the context of experimental and orthotopic models of metastasis would potentially identify modulators of metastasis without prior knowledge of the selective pressures faced by cancer cells. The Hynes, Massague, and Weinberg laboratories have already used in vivo selection of rare metastatic variants from human cancer cell lines in combination with transcriptional profiling to identify groups of genes whose altered expression correlates with metastatic activity (Clark et al. 2000; Kang et al. 2003; Yang et al. 2004; Minn et al. 2005). A subset of these genes has been found to contribute to the metastatic phenotype and is predictive of metastatic occurrence in patients (Minn et al. 2005). Applying RNAi-based libraries to such experimental designs may enable the identification of gene sets that play a role in metastasis without relying on altered gene expression of these modulators. Similar unbiased genetic screens could also be used to interrogate mechanisms of oncogene addiction and chemoresistance in already established mouse models.

\section{DISCOVERING CANCER VULNERABILITIES: SYNTHETIC LETHAL SCREENS}

Establishing the gene networks that regulate known oncogenes and tumor suppressors and elucidating additional networks that govern cancer cell phenotypes will provide new targets to explore for cancer therapeutics. As 
mentioned above, current targeted cancer therapies are predominantly based on the principles of oncogene addiction. These therapies take advantage of the fact that tumor cells have greater sensitivity to pharmacological inhibition of their dysregulated signaling pathways than their untransformed counterparts. Thus, these targeted therapies exhibit enhanced tumor-selective killing relative to conventional chemotherapeutics by taking advantage of this genetic dependency. The ideal therapeutic target is a protein that is only essential in tumor cells but not normal cells. This type of genetic interaction, where a mutation alone is compatible with viability, but in combination with another lesion leads to death, is referred to as synthetic lethality.

Screening for synthetic lethal gene interactions has been commonly used to dissect signaling pathways and phenotypes in model organisms (for review, see Guarente 1993). Identifying target genes that exhibit synthetic lethality with cancer-associated mutations promises to be fertile ground for cancer therapeutics. Such synthetic lethal interactions are particularly appealing for molecular lesions that are not "druggable" (e.g., loss-of-function mutations in tumor suppressors) or are essential to normal physiological processes. For instance, inhibitors of mTOR have been described to be selectively toxic to PTEN $^{-1-}$ tumors (as well as PTEN $^{-1-}$ isogenic MEFs) at concentrations that do not affect the viability of $\mathrm{PTEN}^{+/+}$ cells, indicating that loss of mTOR activity is synthetically lethal with PTEN dysfunction (Neshat et al. 2001). Likewise, elevated expression of the MYC oncogene in human fibroblasts and cancer cells confers hypersensitivity to agonists of the death receptor DR5 (including the TRAIL ligand, discussed above) (Wang et al. 2004), providing an attractive therapeutic opportunity for the vast number of human cancers that exhibit MYC overexpression. These synthetic lethal interactions have been rationalized based on their connections in biochemical pathways. Recently, Ashworth and colleagues described an unexpected sensitivity of cells lacking the tumor suppressors BRCA $1^{-/}$or BRCA2 $2^{-/-}$to inhibition of Poly(ADPribose) polymerase (PARP) (Farmer et al. 2005). This sensitivity was postulated to result from dysfunction in two complementary pathways of DNA repair: base excision repair (PARP) and double-strand-break repair by homologous recombination (BRCA1, BRCA2). Collectively, these synthetic lethal interactions emphasize the idea that the oncogenic lesions of cancer cells expose unique vulnerabilities and thus provide novel therapeutic opportunities.

These successes of exploiting synthetic lethality for specific tumor cell killing were discovered, at least in part, by hypothesis-driven experiments. However, this candidate gene approach is severely limited by our incomplete understanding of mammalian signaling networks as well as its inherent low-throughput nature. Instead, high-throughput chemical and genetic screening methods enable the unbiased identification of synthetic interactions with cancer genes. Proof-of-principle chemical screens for synthetic lethality have already emerged. Kinzler and colleagues identified compounds that exhibited selective toxicity toward a colon cancer cell line har- boring an endogenous activating mutation of K-Ras but not toward an isogenic derivative in which the K-Ras mutant was deleted (Torrance et al. 2001). Using a similar approach, Fantin et al. (2002) isolated a compound that inhibits the proliferation of mouse and human breast cancer cells overexpressing HER2/neu. Stockwell and colleagues identified compounds that selectively kill engineered tumorigenic cells but not their isogenic counterparts (Dolma et al. 2003). In addition to a novel compound, this strategy uncovered several current anticancer therapies that exhibit genotypic specificity, suggesting that the efficacy of some current therapies may be improved when administered to patients respective of tumor genotypes.

Whereas these screens underscore the potential for identifying vulnerabilities specific to cancer cells, the utility of chemical-based screens is hampered by the often difficult endeavor of drug-target identification. In contrast, the application of RNAi to such loss-of-function synthetic lethality screens offers the potential to interrogate gene-gene interactions and rapidly identify candidate targets. Identifying synthetic lethal interactions in mammalian cells has already been demonstrated with an array-format siRNA library. In a screen for modifiers of TRAIL-induced killing (discussed above), Cooke and colleagues identified siRNAs that inhibited (ex. MYC) or enhanced (AKT1) TRAIL-mediated cell death (AzaBlanc et al. 2003). Validating this screen, the synthetic lethal interaction between ectopic MYC expression and TRAIL signaling was discovered independently by Quon and coworkers (Wang et al. 2004).

As discussed above, applying genome-wide arraybased siRNA screens in mammalian cells is not amenable to use in most individual laboratories. Alternatively, large collections of retrovirus-encoded shRNA libraries could be applied as pools in synthetic lethality screens. However, this strategy has two essential requirements: (1) the capability to track individual shRNA fitness in complex populations, and (2) an shRNA expression system that yields high-penetrance loss of function.

To monitor the relative abundance of shRNAs within a pooled population, we and other investigators have proposed the use of a DNA-bar-coding strategy that has been previously applied in Escherichia coli and subsequently in the Saccharomyces cerevisiae gene-knockout collections (Hensel et al. 1995; Shoemaker et al. 1996; Winzeler et al. 1999; Giaever et al. 2002). Adapted to shRNA libraries, this approach relies on a random 60-nucleotide DNA sequence that is unique to each individual shRNA expression vector (Paddison et al. 2004). A parallel approach relies on the shRNA-encoding gene itself as the bar code identifier (Berns et al. 2004). By PCR amplification of the integrated bar codes from cell populations, one can measure bar code abundance by hybridization to custom microarrays on which the complementary sequences have been printed (Fig. 1). As such, the fitness of cells expressing a given shRNA can be followed by measuring the relative abundance of the linked bar code sequences under control and experimental conditions. We have recently demonstrated the first successful application of this approach in mammalian cells 


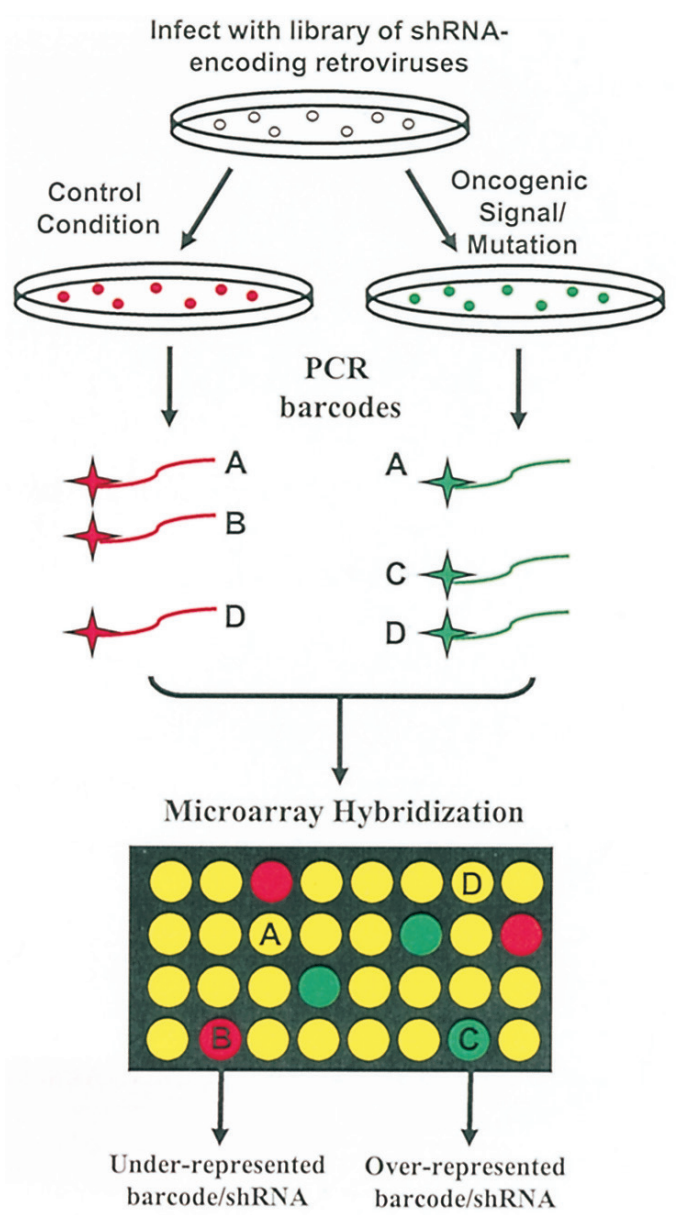

Figure 1. Schematic representation of pooled strategy for using molecular bar codes to track shRNAs in complex populations. Target cells are infected with a retroviral shRNA library, with each shRNA-expressing virus also encoding a unique 60 -bp sequence, or molecular bar code. Infected cells are exposed to control or experimental conditions (e.g., oncogene or tumor suppressor lesion). Bar codes are PCR-amplified from the resulting populations and transcribed, incorporating fluorescent nucleotides. cRNA is used to hybridize to complementary bar codes printed on a custom microarray, thus quantitating the relative changes in any given bar code between the two populations. Individual bar codes are represented by A, B, C, and D, with B and $C$ representing bar codes with lower and higher fitness, respectively, in the presence of the experimental condition.

(Westbrook et al. 2005). To identify candidate tumor suppressors (discussed above), we screened for shRNAs that elicited anchorage-independent proliferation in pre-transformed HMECs. Resultant anchorage-independent colonies were pooled and assessed for the enrichment of bar codes linked to the individual shRNAs. Sequencing of individual proviral shRNAs and bar codes confirmed the efficacy of the bar code microarrays in identifying the corresponding shRNA population, thus validating this approach in the context of enrichment screens. However, the use of the bar code approach to measure the loss of shRNAs from a complex population of cells is more challenging and has not yet been demonstrated.

Although several technical and biological factors may affect the use of pooled shRNA collections in synthetic lethality screens, the most confounding issue regards the penetrance of shRNA-mediated silencing. The application of bar-coding strategies requires the shRNA-expressing retroviruses to be present as single integrants. However, expression of transgenes from retroviral constructs has been shown to be highly variable, depending on the genomic context of integration, suggesting that the efficacy of any given shRNA would also vary across a population of independent integrants. Indeed, although several systems for shRNA expression have been generated, these systems have typically relied on multiple integrations per cell to achieve knockdown of a gene of interest in pooled populations (Wiznerowicz and Trono 2003; Malphettes and Fussenegger 2004; Tiscornia et al. 2004; Ventura et al. 2004; Zhou et al. 2005), indicating that current shRNA expression systems are inadequate for bar-code-based synthetic lethal screens.

Recent studies suggest that this obstacle to synthetic lethality screens might be overcome with a new shRNA expression vector design. This lentiviral system incorporates two novel features that, together, confer high-penetrance knockdown of a given target gene from singlecopy proviral shRNA transgenes (Dickins et al. 2005; Silva et al. 2005; Stegmeier et al. 2005). First, the shRNA sequence is embedded within the context of miR30 (Silva et al. 2005), a naturally occurring microRNA transcript whose biogenesis has been previously characterized (Cullen 2004). Cullen and colleagues have shown that artificial sequences inserted within this transcript can effectively reduce the levels of a synthetic target mRNA containing the appropriate complementary sequence (Zeng et al. 2002). We have exploited this observation by embedding libraries of shRNAs directed against human and mouse genes into a miR30 context (Fig. 2). In a direct comparison of vectors encoding simple shRNA transcripts with $\mathrm{pSM} 2$, transient transfection experiments indicate that the miR30 context significantly improves the expression of the mature siRNA sequence as well as consequent knockdown of target mRNAs (Silva et al. 2005). However, single-copy integration of the synthetic miR30-shRNA transgene is still not sufficient to elicit robust target mRNA knockdown when expressed from the pol III promoters (e.g., U6, H1) that are typically used to transcribe artificial shRNAs (Stegmeier et al. 2005). Fortuitously, we have discovered that the synthetic miR30shRNA elicits significantly improved knockdown of a target gene when transcribed from the cytomegalovirus (CMV) promoter (Fig. 2). This is in agreement with recent reports that endogenous microRNAs are transcribed predominantly by pol II (Cai et al. 2004). Interestingly, target mRNA knockdown is substantially higher when sequences are inserted between the CMV promoter and the miR30-shRNA, suggesting that spacing parameters may contribute to the synthetic miRNA processing or function (Fig. 2) (Stegmeier et al. 2005). This observation enabled us to incorporate various genes encoding fluorescent proteins or antibiotic-resistance markers upstream of the miRNA-shRNA, thus allowing one to track or select populations of cells that express the miRNAshRNA transcript. Most importantly, single-copy integration of this lentiviral vector system elicits highly pene- 

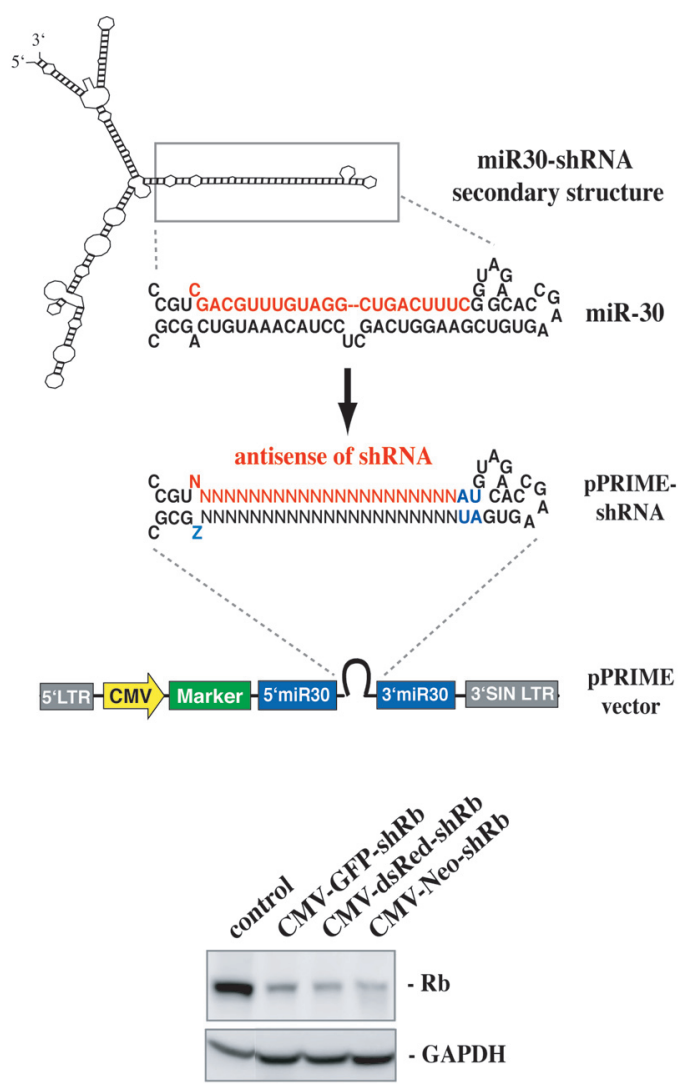

Figure 2. Pol II-driven miR30-embedded shRNAs effectively silence target gene expression at single copy. Schematic representation of an shRNA sequence incorporated into miR30 within the pPRIME vector (Potent $R$ NA Interference using MicroRNA Expression). Secondary structure of the miR30-shRNA hybrid is shown as predicted by RNAFOLD (http://rna.tbi.univie.ac.at/ cgi-bin/RNAfold.cgi). The pPRIME vector series incorporates genes encoding antibiotic-resistance markers or fluorescent proteins within the same transcript as the miR30-shRNA. In the bottom panel, the tumor suppressor Rb was targeted with an shRNA expressed from three different pPRIME derivatives. Cells were infected at an moi of $<0.3$, and transduced cells were isolated by Neomycin selection or fluorescence-activated cell sorting. Approximately 1 week post-infection, cell lysates were analyzed for $\mathrm{Rb}$ expression by western blot.

trant knockdown of the target gene, as measured in pooled populations and individual clones (Fig. 2) (Stegmeier et al. 2005). This innovation, coupled with the bar-coding strategy, will facilitate the use of shRNA libraries in genome-scale loss-of-function screens. In particular, these advances should foster the use of synthetic lethal approaches to study a variety of biological processes in addition to cancer biology.

\section{FUTURE DIRECTIONS OR CONCLUSIONS}

Since President Nixon declared war on cancer in 1971, we have made significant progress in deciphering the molecular lesions that contribute to tumor formation. However, the therapeutic options for treating most cancers is still a frustrating and often futile exercise. Traditional chemotherapeutics (such as DNA-damaging and anti-mitotic agents) are often plagued by tremendous side effects due to their inability to discriminantly kill cancer over normal proliferative tissues. However, the recent successes of targeted molecular therapy (such as Imatinib and Herceptin) present good examples of how our increased molecular understanding of aberrant cancer cell signaling can lead to more efficient therapies. Importantly, these targeted drugs illustrate that many genetic changes within cancer cells will create vulnerabilities that can be exploited for the development of more specific therapies. One promising way to reveal such vulnerabilities is to search for synthetic lethal interactions with the tumor-specific lesions. The synthetic lethal approach has not been exploited in the past because there were no robust methods for systematically identifying synthetic lethal genes. However, recent advances in chemical genetics and RNAi technology will undoubtedly facilitate the discovery of promising new drug targets and perhaps help us to finally win the war on cancer.

\section{ACKNOWLEDGMENTS}

We acknowledge members of the Elledge and Hannon laboratories and all those whose work was not cited due to constraints of space and scope.

\section{REFERENCES}

Ashkenazi A. and Dixit V.M. 1999. Apoptosis control by death and decoy receptors. Curr. Opin. Cell Biol. 11: 255.

Ashrafi K., Chang F.Y., Watts J.L., Fraser A.G., Kamath R.S., Ahringer J., and Ruvkun G. 2003. Genome-wide RNAi analysis of Caenorhabditis elegans fat regulatory genes. Nature 421: 268.

Aza-Blanc P., Cooper C.L., Wagner K., Batalov S., Deveraux Q.L., and Cooke M.P. 2003. Identification of modulators of TRAIL-induced apoptosis via RNAi-based phenotypic screening. Mol. Cell 12: 627.

Baeg G.H., Zhou R., and Perrimon N. 2005. Genome-wide RNAi analysis of JAK/STAT signaling components in Drosophila. Genes Dev. 19: 1861.

Berns K., Hijmans E.M., Mullenders J., Brummelkamp T.R., Velds A., Heimerikx M., Kerkhoven R.M., Madiredjo M., Nijkamp W., Weigelt B., Agami R., Ge W., Cavet G., Linsley P.S., Beijersbergen R.L., and Bernards R. 2004. A large-scale RNAi screen in human cells identifies new components of the p53 pathway. Nature 428: 431.

Bernstein E., Caudy A.A., Hammond S.M., and Hannon G.J. 2001. Role for a bidentate ribonuclease in the initiation step of RNA interference. Nature 409: 363.

Boutros M., Kiger A.A., Armknecht S., Kerr K., Hild M., Koch B., Haas S.A., Consortium H.F., Paro R., and Perrimon N. 2004. Genome-wide RNAi analysis of growth and viability in Drosophila cells. Science 303: 832.

Brummelkamp T.R. and Bernards R. 2003. New tools for functional mammalian cancer genetics. Nat. Rev. Cancer 3: 781.

Brummelkamp T.R., Bernards R., and Agami R. 2002. A system for stable expression of short interfering RNAs in mammalian cells. Science 296: 550.

Brummelkamp T.R., Nijman S.M., Dirac A.M., and Bernards R. 2003. Loss of the cylindromatosis tumour suppressor inhibits apoptosis by activating NF-kappaB. Nature 424: 797.

Cai X., Hagedorn C.H., and Cullen B.R. 2004. Human micro RNAs are processed from capped, polyadenylated transcripts that can also function as mRNAs. RNA 10: 1957.

Chambers A.F., Groom A.C., and MacDonald I.C. 2002. Dissemination and growth of cancer cells in metastatic sites. Nat. Rev. Cancer 2: 563.

Chong J.A., Tapia-Ramirez J., Kim S., Toledo-Aral J.J., Zheng 
Y., Boutros M.C., Altshuller Y.M., Frohman M.A., Kraner S.D., and Mandel G. 1995. REST: A mammalian silencer protein that restricts sodium channel gene expression to neurons. Cell 80: 949.

Clark E.A., Golub T.R., Lander E.S., and Hynes R.O. 2000. Genomic analysis of metastasis reveals an essential role for RhoC. Nature 406: 532.

Cools J., DeAngelo D.J., Gotlib J., Stover E.H., Legare R.D., Cortes J., Kutok J., Clark J., Galinsky I., Griffin J.D., Cross N.C., Tefferi A., Malone J., Alam R., Schrier S.L., Schmid J., Rose M., Vandenberghe P., Verhoef G., Boogaerts M., Wlodarska I., Kantarjian H., Marynen P., Coutre S.E., Stone R., and Gilliland D.G. 2003. A tyrosine kinase created by fusion of the PDGFRA and FIP1L1 genes as a therapeutic target of imatinib in idiopathic hypereosinophilic syndrome. N. Engl. J. Med. 348: 1201.

Cullen B.R. 2004. Transcription and processing of human microRNA precursors. Mol. Cell 16: 861.

D'Andrea A. 2003. Fanconi anemia. Curr. Biol. 13: R546.

DasGupta R., Kaykas A., Moon R.T., and Perrimon N. 2005. Functional genomic analysis of the Wnt-wingless signaling pathway. Science 308: 826.

Demetri G.D., von Mehren M., Blanke C.D., Van den Abbeele A.D., Eisenberg B., Roberts P.J., Heinrich M.C., Tuveson D.A., Singer S., Janicek M., Fletcher J.A., Silverman S.G., Silberman S.L., Capdeville R., Kiese B., Peng B., Dimitrijevic S., Druker B.J., Corless C., Fletcher C.D., and Joensuu H. 2002. Efficacy and safety of imatinib mesylate in advanced gastrointestinal stromal tumors. N. Engl. J. Med. 347: 472.

Dickins R.A., Hemann M.T., Zilfou J.T., Simpson D.R., Ibarra I., Hannon G.J., and Lowe S.W. 2005. Probing tumor phenotypes using stable and regulated synthetic microRNA precursors. Nat. Genet. 37: 1289.

Dolma S., Lessnick S.L., Hahn W.C., and Stockwell B.R. 2003. Identification of genotype-selective antitumor agents using synthetic lethal chemical screening in engineered human tumor cells. Cancer Cell 3: 285.

Douma S., Van Laar T., Zevenhoven J., Meuwissen R., Van Garderen E., and Peeper D.S. 2004. Suppression of anoikis and induction of metastasis by the neurotrophic receptor TrkB. Nature 430: 1034.

Druker B.J. 2002. STI571 (Gleevec) as a paradigm for cancer therapy. Trends Mol. Med. 8: S14.

Druker B.J., Tamura S., Buchdunger E., Ohno S., Segal G.M., Fanning S., Zimmermann J., and Lydon N.B. 1996. Effects of a selective inhibitor of the Abl tyrosine kinase on the growth of Bcr-Abl positive cells. Nat. Med. 2: 561.

Druker B.J., Talpaz M., Resta D.J., Peng B., Buchdunger E., Ford J.M., Lydon N.B., Kantarjian H., Capdeville R., OhnoJones S., and Sawyers C.L. 2001. Efficacy and safety of a specific inhibitor of the BCR-ABL tyrosine kinase in chronic myeloid leukemia. N. Engl. J. Med. 344: 1031.

Dykxhoorn D.M., Novina C.D., and Sharp P.A. 2003. Killing the messenger: Short RNAs that silence gene expression. Nat. Rev. Mol. Cell Biol. 4: 457.

Elbashir S.M., Harborth J., Lendeckel W., Yalcin A., Weber K., and Tuschl T. 2001. Duplexes of 21-nucleotide RNAs mediate RNA interference in cultured mammalian cells. Nature 411: 494.

Fantin V.R., Berardi M.J., Scorrano L., Korsmeyer S.J., and Leder P. 2002. A novel mitochondriotoxic small molecule that selectively inhibits tumor cell growth. Cancer Cell 2: 29.

Farmer H., McCabe N., Lord C.J., Tutt A.N., Johnson D.A., Richardson T.B., Santarosa M., Dillon K.J., Hickson I., Knights C., Martin N.M., Jackson S.P., Smith G.C., and Ashworth A. 2005. Targeting the DNA repair defect in BRCA mutant cells as a therapeutic strategy. Nature 434: 917.

Fire A., Xu S., Montgomery M.K., Kostas S.A., Driver S.E., and Mello C.C. 1998. Potent and specific genetic interference by double-stranded RNA in Caenorhabditis elegans. Nature 391: 806.

Giaever G., Chu A.M., Ni L., Connelly C., Riles L., Veronneau S., Dow S., Lucau-Danila A., Anderson K., Andre B., Arkin A.P., Astromoff A., El-Bakkoury M., Bangham R., Benito R.,
Brachat S., Campanaro S., Curtiss M., Davis K., Deutschbauer A., Entian K.D., Flaherty P., Foury F., Garfinkel D.J., and Gerstein M., et al. 2002. Functional profiling of the Saccharomyces cerevisiae genome. Nature 418: 387.

Goldfarb M., Shimizu K., Perucho M., and Wigler M. 1982. Isolation and preliminary characterization of a human transforming gene from T24 bladder carcinoma cells. Nature 296: 404.

Gorre M.E., Mohammed M., Ellwood K., Hsu N., Paquette R., Rao P.N., and Sawyers C.L. 2001. Clinical resistance to STI571 cancer therapy caused by BCR-ABL gene mutation or amplification. Science 293: 876.

Grishok A., Pasquinelli A.E., Conte D., Li N., Parrish S., Ha I., Baillie D.L., Fire A., Ruvkun G., and Mello C.C. 2001. Genes and mechanisms related to RNA interference regulate expression of the small temporal RNAs that control C. elegans developmental timing. Cell 106: 23.

Guarente L. 1993. Synthetic enhancement in gene interaction: A genetic tool come of age. Trends Genet. 9: 362 .

Hamilton B., Dong Y., Shindo M., Liu W., Odell I., Ruvkun G., and Lee S.S. 2005. A systematic RNAi screen for longevity genes in C. elegans. Genes Dev. 19: 1544.

Hanahan D. and Weinberg R.A. 2000. The hallmarks of cancer. Cell 100: 57.

Hannon G.J. 2002. RNA interference. Nature 418: 244.

Hannon G.J. and Rossi J.J. 2004. Unlocking the potential of the human genome with RNA interference. Nature 431: 371.

Hensel M., Shea J.E., Gleeson C., Jones M.D., Dalton E., and Holden D.W. 1995. Simultaneous identification of bacterial virulence genes by negative selection. Science 269: 400.

Hutvagner G., McLachlan J., Pasquinelli A.E., Balint E., Tuschl T., and Zamore P.D. 2001. A cellular function for the RNAinterference enzyme Dicer in the maturation of the let-7 small temporal RNA. Science 293: 834.

Jonkers J. and Berns A. 2002. Conditional mouse models of sporadic cancer. Nat. Rev. Cancer 2: 251.

. 2004. Oncogene addiction: Sometimes a temporary slavery. Cancer Cell 6: 535.

Kang Y., Siegel P.M., Shu W., Drobnjak M., Kakonen S.M., Cordon-Cardo C., Guise T.A., and Massague J. 2003. A multigenic program mediating breast cancer metastasis to bone. Cancer Cell 3: 537.

Ketting R.F., Fischer S.E., Bernstein E., Sijen T., Hannon G.J., and Plasterk R.H. 2001. Dicer functions in RNA interference and in synthesis of small RNA involved in developmental timing in C. elegans. Genes Dev. 15: 2654.

Kittler R., Putz G., Pelletier L., Poser I., Heninger A.K., Drechsel D., Fischer S., Konstantinova I., Habermann B., Grabner H., Yaspo M.L., Himmelbauer H., Korn B., Neugebauer K., Pisabarro M.T., and Buchholz F. 2004. An endoribonucleaseprepared siRNA screen in human cells identifies genes essential for cell division. Nature 432: 1036.

Lee S.S., Lee R.Y., Fraser A.G., Kamath R.S., Ahringer J., and Ruvkun G. 2003. A systematic RNAi screen identifies a critical role for mitochondria in C. elegans longevity. Nat. Genet. 33: 40.

Lin S.Y. and Elledge S.J. 2003. Multiple tumor suppressor pathways negatively regulate telomerase. Cell 113: 881 .

Logan C.Y. and Nusse R. 2004. The Wnt signaling pathway in development and disease. Annu. Rev. Cell Dev. Biol. 20: 781.

Lum L., Yao S., Mozer B., Rovescalli A., Von Kessler D., Nirenberg M., and Beachy P.A. 2003. Identification of Hedgehog pathway components by RNAi in Drosophila cultured cells. Science 299: 2039.

Lynch T.J., Bell D.W., Sordella R., Gurubhagavatula S., Okimoto R.A., Brannigan B.W., Harris P.L., Haserlat S.M., Supko J.G., Haluska F.G., Louis D.N., Christiani D.C., Settleman J., and Haber D.A. 2004. Activating mutations in the epidermal growth factor receptor underlying responsiveness of non-small-cell lung cancer to gefitinib. N. Engl. J. Med. 350: 2129 .

MacKeigan J.P., Murphy L.O., and Blenis J. 2005. Sensitized RNAi screen of human kinases and phosphatases identifies new regulators of apoptosis and chemoresistance. Nat. Cell Biol. 7: 591 . 
Malphettes L. and Fussenegger M. 2004. Macrolide- and tetracycline-adjustable siRNA-mediated gene silencing in mammalian cells using polymerase II-dependent promoter derivatives. Biotechnol. Bioeng. 88: 417.

Manche L., Green S.R., Schmedt C., and Mathews M.B. 1992. Interactions between double-stranded RNA regulators and the protein kinase DAI. Mol. Cell. Biol. 12: 5238.

Meetei A.R., de Winter J.P., Medhurst A.L., Wallisch M., Waisfisz Q., van de Vrugt H.J., Oostra A.B., Yan Z., Ling C., Bishop C.E., Hoatlin M.E., Joenje H., and Wang W. 2003. A novel ubiquitin ligase is deficient in Fanconi anemia. Nat. Genet. 35: 165.

Meister G. and Tuschl T. 2004. Mechanisms of gene silencing by double-stranded RNA. Nature 431: 343.

Minks M.A., West D.K., Benvin S., and Baglioni C. 1979. Structural requirements of double-stranded RNA for the activation of $2^{\prime}, 5^{\prime}$-oligo(A) polymerase and protein kinase of interferontreated HeLa cells. J. Biol. Chem. 254: 10180.

Minn A.J., Gupta G.P., Siegel P.M., Bos P.D., Shu W., Giri D.D., Viale A., Olshen A.B., Gerald W.L., and Massague J. 2005. Genes that mediate breast cancer metastasis to lung. Nature 436: 518.

Neshat M.S., Mellinghoff I.K., Tran C., Stiles B., Thomas G., Petersen R., Frost P., Gibbons J.J., Wu H., and Sawyers C.L. 2001. Enhanced sensitivity of PTEN-deficient tumors to inhibition of FRAP/mTOR. Proc. Natl. Acad. Sci. 98: 10314.

Nijman S.M., Huang T.T., Dirac A.M., Brummelkamp T.R., Kerkhoven R.M., D'Andrea A.D., and Bernards R. 2005. The deubiquitinating enzyme USP1 regulates the Fanconi anemia pathway. Mol. Cell 17: 331.

Nybakken K. and Perrimon N. 2002. Hedgehog signal transduction: Recent findings. Curr. Opin. Genet. Dev. 12: 503.

Paddison P.J. and Hannon G.J. 2002. RNA interference: The new somatic cell genetics? Cancer Cell 2: 17.

Paddison P.J., Caudy A.A., Bernstein E., Hannon G.J., and Conklin DS. 2002. Short hairpin RNAs (shRNAs) induce sequence-specific silencing in mammalian cells. Genes Dev. 16: 948 .

Paddison P.J., Silva J.M., Conklin D.S., Schlabach M., Li M., Aruleba S., Balija V., O'Shaughnessy A., Gnoj L., Scobie K., Chang K., Westbrook T., Cleary M., Sachidanandam R., McCombie W.R., Elledge S.J., and Hannon G.J. 2004. A resource for large-scale RNA-interference-based screens in mammals. Nature 428: 427.

Paez J.G., Janne P.A., Lee J.C., Tracy S., Greulich H., Gabriel S., Herman P., Kaye F.J., Lindeman N., Boggon T.J., Naoki K., Sasaki H., Fujii Y., Eck M.J., Sellers W.R., Johnson B.E., and Meyerson M. 2004. EGFR mutations in lung cancer: Correlation with clinical response to gefitinib therapy. Science 304: 1497.

Peeper D.S., Shvarts A., Brummelkamp T., Douma S., Koh E.Y., Daley G.Q., and Bernards R. 2002. A functional screen identifies hDRIL1 as an oncogene that rescues RAS-induced senescence. Nat. Cell Biol. 4: 148.

Schoenherr C.J. and Anderson D.J. 1995. The neuron-restrictive silencer factor (NRSF): A coordinate repressor of multiple neuron-specific genes. Science 267: 1360.

Shih C. and Weinberg R.A. 1982. Isolation of a transforming sequence from a human bladder carcinoma cell line. Cell 29: 161.

Shoemaker D.D., Lashkari D.A., Morris D., Mittmann M., and Davis R.W. 1996. Quantitative phenotypic analysis of yeast deletion mutants using a highly parallel molecular bar-coding strategy. Nat. Genet. 14: 450.

Shvarts A., Brummelkamp T.R., Scheeren F., Koh E., Daley G.Q., Spits H., and Bernards R. 2002. A senescence rescue screen identifies BCL6 as an inhibitor of anti-proliferative p19(ARF)-p53 signaling. Genes Dev. 16: 681.

Sieburth D., Ch'ng Q., Dybbs M., Tavazoie M., Kennedy S., Wang D., Dupuy D., Rual J.F., Hill D.E., Vidal M., Ruvkun G., and Kaplan J.M. 2005. Systematic analysis of genes required for synapse structure and function. Nature 436: 510 .

Siegel P.M. and Massague J. 2003. Cytostatic and apoptotic actions of TGF-beta in homeostasis and cancer. Nat. Rev. Cancer 3: 807.
Silva J., Chang K., Hannon G.J., and Rivas F.V. 2004. RNA-interference-based functional genomics in mammalian cells: Reverse genetics coming of age. Oncogene 23: 8401.

Silva J.M., Li M.Z., Chang K., Ge W., Golding M.C., Rickles R.J., Siolas D., Hu G., Paddison P.J., Schlabach M.R., Sheth N., Bradshaw J., Burchard J., Kulkarni A., Cavet G., Sachidanandam R., McCombie W.R., Cleary M.A., Elledge S.J., and Hannon G.J. 2005. Second-generation shRNA libraries covering the mouse and human genomes. Nat. Genet. 37: 1281.

Slamon D.J., Godolphin W., Jones L.A., Holt J.A., Wong S.G., Keith D.E., Levin W.J., Stuart S.G., Udove J., and Ullrich A., et al. 1989. Studies of the HER-2/neu proto-oncogene in human breast and ovarian cancer. Science 244: 707.

Sordella R., Bell D.W., Haber D.A., and Settleman J. 2004. Gefitinib-sensitizing EGFR mutations in lung cancer activate anti-apoptotic pathways. Science 305: 1163.

Stark G.R., Kerr I.M., Williams B.R., Silverman R.H., and Schreiber R.D. 1998. How cells respond to interferons. Annu. Rev. Biochem. 67: 227.

Stegmeier F., Hu G., Rickles R.J., Hannon G.J., and Elledge S.J. 2005. A lentiviral microRNA-based system for single-copy polymerase II-regulated RNA interference in mammalian cells. Proc. Natl. Acad. Sci. 102: 13212.

Sui G., Soohoo C., Affar el B., Gay F., Shi Y., and Forrester W.C. 2002. A DNA vector-based RNAi technology to suppress gene expression in mammalian cells. Proc. Natl. Acad. Sci. 99: 5515 .

Tiscornia G., Tergaonkar V., Galimi F., and Verma I.M. 2004. CRE recombinase-inducible RNA interference mediated by lentiviral vectors. Proc. Natl. Acad. Sci. 101: 7347.

Torrance C.J., Agrawal V., Vogelstein B., and Kinzler K.W. 2001. Use of isogenic human cancer cells for high-throughput screening and drug discovery. Nat. Biotechnol. 19: 940.

Tuveson D.A., Willis N.A., Jacks T., Griffin J.D., Singer S., Fletcher C.D., Fletcher J.A., and Demetri G.D. 2001. STI571 inactivation of the gastrointestinal stromal tumor c-KIT oncoprotein: Biological and clinical implications. Oncogene 20: 5054.

Ventura A., Meissner A., Dillon C.P., McManus M., Sharp P.A., Van Parijs L., Jaenisch R., and Jacks T. 2004. Cre-lox-regulated conditional RNA interference from transgenes. Proc. Natl. Acad. Sci. 101: 10380.

Vivanco I. and Sawyers C.L. 2002. The phosphatidylinositol 3kinase AKT pathway in human cancer. Nat. Rev. Cancer 2: 489.

Wang Y., Engels I.H., Knee D.A., Nasoff M., Deveraux Q.L., and Quon K.C. 2004. Synthetic lethal targeting of MYC by activation of the DR5 death receptor pathway. Cancer Cell 5: 501.

Weinstein I.B. 2002. Cancer. Addiction to oncogenes: The Achilles heal of cancer. Science 297: 63.

Westbrook T.F., Martin E.S., Schlabach M.R., Leng Y., Liang A.C., Feng B., Zhao J.J., Roberts T.M., Mandel G., Hannon G.J., Depinho R.A., Chin L., and Elledge S.J. 2005. A genetic screen for candidate tumor suppressors identifies REST. Cell 121: 837.

Willingham A.T., Deveraux Q.L., Hampton G.M., and AzaBlanc P. 2004. RNAi and HTS: Exploring cancer by systematic loss-of-function. Oncogene 23: 8392.

Winzeler E.A., Shoemaker D.D., Astromoff A., Liang H., Anderson K., Andre B., Bangham R., Benito R., Boeke J.D., Bussey H., Chu A.M., Connelly C., Davis K., Dietrich F., Dow S.W., El Bakkoury M., Foury F., Friend S.H., Gentalen E., Giaever G., Hegemann J.H., Jones T., Laub M., Liao H., and R.W. Davis, et al. 1999. Functional characterization of the $S$. cerevisiae genome by gene deletion and parallel analysis. Science 285: 901.

Wiznerowicz M. and Trono D. 2003. Conditional suppression of cellular genes: Lentivirus vector-mediated drug-inducible RNA interference. J. Virol. 77: 8957.

Yang J., Mani S.A., Donaher J.L., Ramaswamy S., Itzykson R.A., Come C., Savagner P., Gitelman I., Richardson A., and Weinberg RA. 2004. Twist, a master regulator of morpho- 
genesis, plays an essential role in tumor metastasis. Cell 117: 927.

Yu J.Y., DeRuiter S.L., and Turner D.L. 2002. RNA interference by expression of short-interfering RNAs and hairpin RNAs in mammalian cells. Proc. Natl. Acad. Sci. 99: 6047.

Zeng Y., Wagner E.J., and Cullen B.R. 2002. Both natural and designed micro RNAs can inhibit the expression of cognate mRNAs when expressed in human cells. Mol. Cell 9: 1327.
Zheng L., Liu J., Batalov S., Zhou D., Orth A., Ding S., and Schultz P.G. 2004. An approach to genomewide screens of expressed small interfering RNAs in mammalian cells. Proc. Natl. Acad. Sci. 101: 135.

Zhou H., Xia X.G., and Xu Z. 2005. An RNA polymerase II construct synthesizes short-hairpin RNA with a quantitative indicator and mediates highly efficient RNAi. Nucleic Acids Res. 33: e62. 


\section{$\overbrace{\mathrm{CSH}}^{\infty}$ Cold Spring Harbor Symposia SYMPOSIA on Quantitative Biology}

\section{Dissecting Cancer Pathways and Vulnerabilities with RNAi}

T.F. WESTBROOK, F. STEGMEIER and S.J. ELLEDGE

Cold Spring Harb Symp Quant Biol 2005 70: 435-444

Access the most recent version at doi:10.1101/sqb.2005.70.031

References This article cites 95 articles, 29 of which can be accessed free at: http://symposium.cshlp.org/content/70/435.full.html\#ref-list-1

\section{License}

Email Alerting Receive free email alerts when new articles cite this article - sign up in Service the box at the top right corner of the article or click here. 